\title{
Effect of Magnesium Deficiency on Renal Magnesium and Calcium Transport in the Rat
}

\author{
Shane L. Carney, Norman L. M. Wong, Gary A. Quamme, and John H. Dirks, \\ Department of Medicine, University of British Columbia, Vancouver, \\ British Columbia V5Z 1M9, Canada
}

\begin{abstract}
A B S T R A C T Recollection of micropuncture experiments were performed on acutely thyroparathyroidectomized rats rendered magnesium deficient by dietary deprivation. Urinary magnesium excretion fell from a control of 15 to $3 \%$ of the filtered load after magnesium restriction. The loop of Henle, presumably the thick ascending limb, was the major modulator for renal magnesium homeostasis. The transport capacity for magnesium, however, was less in deficient rats than control animals. Absolute magnesium reabsorption increased with acute infusions of magnesium chloride but was always less in magnesium-deficient rats than control rats for any given filtered load, which suggests either a defect of a resetting of the reabsorption mechanism. Recollection micropuncture demonstrated that this was a characteristic of the loop of Henle. Proximal magnesium reabsorption remained unchanged at $15 \%$ of the filtered load and was unaffected by magnesium deficiency or acute magnesium repletion. Distal tubular magnesium reabsorption was limited during depletion and increased to a similar extent in control and deficient rats with enhanced magnesium delivery. Calcium reabsorption was not altered in magnesium deficiency; however, elevations of extracellular magnesium resulted in a specific inhibition of calcium reabsorption within the loop of Henle. These data suggest that overall control of renal magnesium reabsorption occurs within the loop of Henle and that the proximal tubule reabsorbs a constant fraction of the filtered load despite variations in body magnesium status.
\end{abstract}

\section{INTRODUCTION}

The mechanisms controlling magnesium handling by the kidney are not known, particularly those which are

This work was presented in part at the Annual Meeting of The American Society for Clinical Investigation, San Francisco, Calif., 1 May 1978, and was published in abstract form in: Clin. Res. 1978. 26: 540A.

Dr. Carney was a Fellow of the Medical Research Council (Canada).

Received for publication 13 July 1978 and in revised form 4 September 1979. involved in limiting urinary magnesium excretion in dietary magnesium deprivation (1-7). The kidney responds to magnesium deficiency in a manner to efficiently conserve filtered magnesium $(5,8-12)$. The tubular sites involved in magnesium reabsorption and the method of adaptation to magnesium depletion have not previously been investigated by micropuncture techniques. Our experiments were performed to determine the nephron sites and mechanisms involved in renal tubule handling of magnesium and other electrolytes in magnesium-deficient rats as compared with normal rats using recollection micropuncture techniques. Furthermore, additional studies were done to determine the reabsorptive capacity of the magnesium-deficient kidney to respond to an enhanced magnesium delivery. The data presented demonstrate the unique functioning of the kidney and particularly the loop of Henle in magnesium deficiency and the inability to adjust the transport capacity in response to increased magnesium delivery.

\section{METHODS}

Male Wistar rats weighing between 170 and $210 \mathrm{~g}$ were used in this study. Magnesium depletion was induced by feeding a diet that contained $0.01 \mathrm{~g}$ of magnesium per $100 \mathrm{~g}$ of diet (ICN Nutritional Biochemicals, Cleveland, Ohio) for 7-10 d, in which all other dietary constituents were present in adequate amounts. A pair-fed normal control group received the same diet supplemented with magnesium $(0.41 \mathrm{~g} / 100 \mathrm{~g})$ in the sulfate form. Distilled drinking water was allowed ad lib. Inactin (Promonta, Hamburg, West Germany) $100 \mathrm{mg} / \mathrm{kg}$ administered intraperitoneally was used for anesthesia in nonfasted animals, and the animals were placed on a heated table to maintain body temperature between 37 and $38^{\circ} \mathrm{C}$. After tracheostomy, thyroparathyroidectomy (TPTX) ${ }^{1}$ was performed by electrocautery, and the jugular vein, left carotid artery, and bladder were cannulated with polyethylene tubing (PE50). The left kidney was then exposed by a subcostal incision

${ }^{1}$ Abbreviations used in this paper: GFR, glomerular filtration rate; Mg I, mild magnesium loading; Mg II, moderate magnesum loading; (P/TF)In, plasma:tubular fluid inulin concentration ratio; (TF/P)In, tubular fluid:plasma inulin concentration ratio; $(\mathrm{TF} / \mathrm{UF})_{\mathrm{Ca}}$, tubular fluid:ultrafilterable calcium ratio; $(\mathrm{TF} / \mathrm{UF})_{\mathrm{Mg}}$, tubular fluid:ultrafilterable magnesium ratio; TPTX, thyroparathyroidectomy/ized. 
and prepared for micropuncture by removal of surrounding fat and connective tissue and by immobilization in situ in a glass dish. The exposed kidney was then covered with agar and a small area was uncovered and bathed with heated, $38^{\circ} \mathrm{C}$ mineral oil. The kidney surface was illuminated with a fiber optic light, and late proximal as well as early and late distal puncture sites were identified by intratubule injections of lissamine green (10-20 $\mathrm{nl}$ of a $1 \%$ solution). An infusion of magnesium-free Ringer's solution ( $\mathrm{NaCl} 140, \mathrm{KCl} 3, \mathrm{CaCl}_{2} 3$ meq/liter) with $2 \%$ inulin was commenced at a rate of $130 \mu \mathrm{l} / \mathrm{min}$ for $15 \mathrm{~min}$, and then reduced to $40 \mu \mathrm{l} / \mathrm{min}$ for the remainder of the experiment.

Groups consisting of 6 normal control rats and 14 magnesium-deficient rats were studied during the following three experimental phases.

Control phase. $2 \mathrm{~h}$ after TPTX, urine was collected over two 15-min periods, and a midpoint arterial blood sample $(200 \mu \mathrm{l})$ was taken. Proximal and distal tubular fluid samples were collected during this period.

Mild magnesium loading (Mg I). $0.25 \mathrm{ml}$ of a $100 \mathrm{meq} /$ liter magnesium chloride solution was then administered acutely, and $10 \mathrm{meq} / \mathrm{liter}$ of magnesium chloride was added to the Ringer's sustaining infusion. $30 \mathrm{~min}$ later, urinary clearances and recollection micropuncture sampling were performed as described for the control phase.

Moderate magnesium loading (Mg II). $0.25 \mathrm{ml}$ of a 200 meq/liter magnesium chloride solution was then administered, and the Ringer's magnesium concentration was increased to $40 \mathrm{meq} / \mathrm{liter}$ in lieu of sodium chloride. Urinary clearances and recollection micropuncture sampling were performed after a 30-min interval.

A group of 10 magnesium-deficient rats acted as time controls for the above and received a magnesium-free Ringer's solution throughout the experiment.

Analytical methods. Plasma ultrafiltrates were prepared with Amicon Centriflo ultrafiltration cones (Amicon Corp., Lexington, Mass.) (3) at the termination of each experiment. Urine inulin concentrations were determined by the method of Fuhr et al. (13), and plasma and tubular fluid inulin concentrations were measured by the microfluorometric method of Vurek and Pegram (14). Urine and plasma samples were analyzed for sodium and potassium with a flame photometer (Corning 450, Corning Medical, Corning Glass Works, Medfield, Mass.), calcium and magnesium with an atomic absorption spectrophotometer (Jarrell-Ash 850, Fisher Scientific Co., Pittsburgh, Pa.), and phosphate by the colorimetric method of Chen et al. (15). A Camebax electron microprobe (Cameca Instruments, Inc., Stamford, Conn.) was used for analysis of all tubule fluid electrolytes using a method described by Morel and Roinel $(1,16)$. Comparison of magnesium concentrations measured by electron microprobe analysis and atomic absorption spectrophotometer from plasma ultrafiltrates of magnesium-deficient, normal, and hypermagnesemic rats were found to be in close agreement $(r=0.997$, $n=62$ ) over a wide range of concentrations from 0.1 to 8.0 meq/liter. Renal clearance, fractional excretion, and segmental reabsorption rates were calculated by standard formulae. Probability values were analyzed with the Student's $t$ test. Linear regression analysis was performed with the least squares method.

\section{RESULTS}

Clearance and micropuncture data. Compositional analysis determined according to the technique of Greene and Sapirstien (17) revealed that total body magnesium was reduced by $30 \%$ whereas the mean plasma magnesium was depressed by $65 \%$. In addition, significant reductions of total body potassium (10\%) and phosphate (13\%) also occurred after dietary magnesium deprivation. Total body and plasma calcium composition tended to be higher (6\%); however, this was not statistically significant on an unpaired basis.

Table I gives the mean plasma and clearance data for 6 normal and 14 magnesium-deficient, TPTX rats. Fractional excretion was calculated as the ultrafilterable portion of plasma magnesium and calcium. Ultrafilterable magnesium was $76 \%$ of the total plasma value and was independent of absolute plasma concentration. Regression analysis of ultrafilterable magnesium $(y)$ to total plasma magnesium $(x)$ in magnesiumdeficient, normal, and hypermagnesemic rats produced a correlation of $y=0.002+1.314 x ; n=21 ; r=0.999$; $P<0.001$ over a range of $0.2-6.3 \mathrm{meq} / \mathrm{liter}$. Calcium was $67 \%$ ultrafilterable in these same animals and was not altered by absolute magnesium concentration.

Magnesium. The mean body weights of normal and magnesium-depleted groups were similar, being 180 \pm 5 and $177 \pm 4 \mathrm{~g}$, respectively, at the time of experimentation. Control whole kidney glomerular filtration rates (GFR) were also similar between the two groups (Table I) as were mean single nephron GFR in five normal and eight magnesium-deficient rats $(31 \pm 5$ and $25 \pm 3 \mathrm{nl} / \mathrm{min}$, respectively). Plasma magnesium levels were depressed $\sim 50 \%$ with dietary magnesium restriction, and fractional urinary excretion was $3 \%$ compared with $15 \%$ for normomagnesemic animals. Micropuncture data during the control period (Table II, Fig. 1) demonstrate that in both normal and magnesiumdeficient rats the proximal tubular fluid:ultrafilterable magnesium ratio $\left[(\mathrm{TF} / \mathrm{UF})_{\mathrm{Mg}}\right]$ increases along the tubule in both normal and magnesium-deficient groups, although the ratio remained below that for inulin. Thus at the late proximal tubular puncture site of the superficial nephron $\sim 15 \%$ of filtered magnesium had been reabsorbed in both normal and magnesium-deficient groups. The $(\mathrm{TF} / \mathrm{UF})_{\mathrm{Mg}}$ of early distal tubule puncture samples was considerably lower in magnesiumdeficient rats and reflects an increase in the fraction of filtered magnesium reabsorbed within the loop of Henle $(75 \pm 3$ compared with $63 \pm 4 \%, P<0.05$; Table III). However, because of the marked difference in filtered magnesium between the two groups ( 0.99 and $2.43 \mu \mathrm{eq} / \mathrm{min}$ ) absolute magnesium reabsorption within the loop of Henle of the depleted group was only $48 \%$ of values obtained in normal animals. Significant magnesium reabsorption was not demonstrated in the distal tubule of magnesium-deficient animals in association with a low absolute tubule fluid magnesium, and in normal animals, where the concentration was high, only a small degree of magnesium reabsorption (5\%) was detected in the distal segments. The physiological significance of this small change remains to be determined. Differences of $2-7 \%$ between the late distal puncture site and the final urine may reflect an 
TABLE I

Mean Plasma and Urinary Clearance Data from Normal and Magnesium-deficient TPTX Rats during Control Phases and after Graded Magnesium Infusion

\begin{tabular}{lccccccc}
\hline & \multicolumn{3}{c}{ Pair-fed control $(n=6)$} & & \multicolumn{3}{c}{ Mg deficient $(n=14)$} \\
\cline { 2 - 4 } \cline { 7 - 8 } & Control & $\mathrm{Mg} \mathrm{I}$ & $\mathrm{Mg} \mathrm{II}$ & & Control & $\mathrm{Mg} \mathrm{I}$ & $\mathrm{Mg} \mathrm{II}$ \\
\hline $\mathrm{Hct}, \%$ & $44 \pm 1$ & $43 \pm 1$ & $42 \pm 1$ & & $44 \pm 1$ & $44 \pm 1$ & $42 \pm 1$ \\
$\mathrm{P}_{\mathrm{Alb}}$, mg/100 ml & $4.1 \pm 0.1$ & $4.1 \pm 0.2$ & $4.0 \pm 0.2 \ddagger$ & & $4.1 \pm 0.1$ & $4.0 \pm 0.1$ & $3.9 \pm 0.2 \ddagger$ \\
$\mathrm{V}, \mu l /$ min & $12 \pm 1$ & $38 \pm 11 \ddagger$ & $40 \pm 6$ & & $18 \pm 4$ & $23 \pm 4$ & $29 \pm 5 \ddagger$ \\
$\mathrm{C}_{\mathrm{In}}$, ml/min & $2.3 \pm 0.2$ & $2.4 \pm 0.3$ & $2.1 \pm 0.1$ & & $1.9 \pm 0.2$ & $1.8 \pm 0.2$ & $1.8 \pm 0.2$ \\
$\mathrm{P}_{\mathrm{Mg}}$, meq/liter & $1.4 \pm 0.1$ & $1.6 \pm 0.1$ & $2.4 \pm 0.1$ & & $0.7 \pm 0.1$ & $1.1 \pm 0.1$ & $2.1 \pm 0.1$ \\
$\mathrm{FE}_{\mathrm{Mg}}, \%$ & $15 \pm 2$ & $27 \pm 3$ & $51 \pm 3$ & & $3 \pm 1$ & $20 \pm 4$ & $42 \pm 3$ \\
$\mathrm{P}_{\mathrm{Ca}}$, meq/liter & $4.7 \pm 0.2$ & $4.5 \pm 0.1 \ddagger$ & $4.3 \pm 0.1 \ddagger$ & & $5.0 \pm 0.2$ & $4.7 \pm 0.2$ & $4.5 \pm 0.2$ \\
$\mathrm{FE}_{\mathrm{Ca}}, \%$ & $1.5 \pm 0.4$ & $2.7 \pm 0.8 \ddagger$ & $4.6 \pm 1.0$ & & $0.7 \pm 0.2$ & $2.5 \pm 0.8 \ddagger$ & $5.6 \pm 1.3$ \\
$\mathrm{P}_{\mathrm{Na}}$, meq/liter & $147 \pm 2$ & $146 \pm 1$ & $145 \pm 2$ & & $145 \pm 1$ & $144 \pm 1$ & $145 \pm 1$ \\
$\mathrm{FE}_{\mathrm{Na}}, \%$ & $0.4 \pm 0.1$ & $1.1 \pm 0.2 \ddagger$ & $2.3 \pm 0.2$ & & $0.5 \pm 0.1$ & $1.2 \pm 0.3 \ddagger$ & $2.1 \pm 0.5$ \\
$\mathrm{P}_{\mathrm{Pi}}$, mg/100 ml & $8.4 \pm 0.5$ & $8.6 \pm 0.4$ & $9.1 \pm 0.5 \ddagger$ & & $7.1 \pm 0.5$ & $7.4 \pm 0.4$ & $7.0 \pm 0.5$ \\
$\mathrm{FE}_{\mathrm{Pl}}, \%$ & $0.1 \pm 0.1$ & $0.2 \pm 0.2$ & $0.2 \pm 0.1$ & & $0.1 \pm 0.1$ & $0.1 \pm 0.1$ & $0.1 \pm 0.1$ \\
\hline
\end{tabular}

Abbreviations used in this table: Hct, hematocrit; $\mathrm{P}_{\mathrm{Alb}}$, plasma albumin; $\mathrm{V}$, urine flow; $\mathrm{C}_{\mathrm{In}}$, inulin clearance; FE, fractional excretion of filtered electrolyte.

* Values are mean \pm SEM.

t Significance from control: $P<0.05$.

important capacity for magnesium reabsorption within the collecting system of both normal and magnesiumdeficient animals, or may simply reflect heterogeneous function between accessible superficial and deep inaccessible nephrons.
A group of six magnesium-deficient rats were used as time controls for these experiments. The experimental protocol followed was similar to the above groups except that the animals received magnesiumfree Ringer's solution during the three micropuncture

TABLE II

Mean Magnesium and Inulin Micropuncture Data from Pair-fed Control and Magnesium-deficient TPTX Rats during Control and after Graded Magnesium Infusion*

\begin{tabular}{|c|c|c|c|c|c|c|c|c|c|c|c|c|}
\hline & \multicolumn{6}{|c|}{ Proximal tubule } & \multicolumn{6}{|c|}{ Distal tubule } \\
\hline & \multicolumn{3}{|c|}{ Mid } & \multicolumn{3}{|c|}{ Late } & \multicolumn{3}{|c|}{ Early } & \multicolumn{3}{|c|}{ Late } \\
\hline & $(\mathrm{TF} / \mathrm{P}) \mathbf{I n}$ & $(\mathrm{TF} / \mathrm{UF})_{\mathrm{ME}}$ & $\mathbf{R F}$ & $(\mathrm{TF} / \mathrm{P}) \mathrm{In}$ & $(\mathrm{TF} / \mathrm{UF})_{\mathrm{Mg}}$ & $\mathbf{R F}$ & $(\mathrm{TF} / \mathrm{P}) \mathbf{I n}$ & $(\mathrm{TF} / \mathrm{UF})_{\mathrm{Mz}}$ & RF & $(\mathrm{TF} / \mathrm{P}) \mathrm{In}$ & $(\mathrm{TF} / \mathrm{UF})_{\mathrm{Mg}}$ & RF \\
\hline & & & $\%$ & & & $\%$ & & & $\%$ & & & $\%$ \\
\hline \multicolumn{13}{|c|}{$\begin{array}{l}\text { Pair-fed } \\
\text { control } \\
(n=6)\end{array}$} \\
\hline Control & $1.61 \pm 0.05$ & $1.58 \pm 0.12$ & $98 \pm 7$ & $2.08 \pm 0.05$ & $1.77 \pm 0.06$ & $86 \pm 2$ & $4.32 \pm 0.24$ & $0.99 \pm 0.06$ & $23 \pm 2$ & $8.57 \pm 0.68$ & $1.43 \pm 0.22$ & $17 \pm 2$ \\
\hline Mg I & $1.59 \pm 0.07$ & $1.56 \pm 0.07$ & $99 \pm 3$ & $1.92 \pm 0.04$ & $1.75 \pm 0.10$ & $90 \pm 4$ & $4.50 \pm 0.41$ & $1.70 \pm 0.24 t$ & $37 \pm 5$ & $7.63 \pm 0.73$ & $2.05 \pm 0.21\rceil$ & $27 \pm 5$ \\
\hline Mg II & $1.51 \pm 0.05 t$ & $1.43 \pm 0.07$ & $94 \pm 4$ & $1.94 \pm 0.08$ & $1.65 \pm 0.03$ & $86 \pm 3$ & $4.30 \pm 0.20$ & $2.12 \pm 0.12$ & $49 \pm 3$ & $6.78 \pm 0.63 \S$ & $2.97 \pm 0.26 \S$ & $44 \pm 3 \S$ \\
\hline \multicolumn{13}{|c|}{$\begin{array}{l}\text { Magnesium } \\
\quad \text { deficient } \\
(n=9)\end{array}$} \\
\hline Control & $1.54 \pm 0.03$ & $1.48 \pm 0.06$ & $96 \pm 4$ & $2.18 \pm 0.06$ & $1.83 \pm 0.15$ & $84 \pm 6$ & $4.60 \pm 0.19$ & $0.43 \pm 0.08$ & $9 \pm 2$ & $7.68 \pm 0.60$ & $0.65 \pm 0.14$ & $9 \pm 2$ \\
\hline Mg I & $1.51 \pm 0.04$ & $1.45 \pm 0.06$ & $96 \pm 3$ & $1.96 \pm 0.08$ & $1.83 \pm 0.12$ & $93 \pm 4$ & $4.61 \pm 0.25$ & $1.21 \pm 0.34 t$ & $25 \pm 6$ & $7.01 \pm 0.51 \ddagger$ & $1.53 \pm 0.30$ & $21 \pm 4$ \\
\hline $\mathrm{Mg} \mathrm{II}$ & $1.52 \pm 0.03$ & $1.53 \pm 0.09$ & $101 \pm 6$ & $1.93 \pm 0.06$ & $1.72 \pm 0.09$ & $89 \pm 4$ & $4.38 \pm 0.28$ & $2.17 \pm 0.32 \S$ & $49 \pm 4 \S$ & $7.19 \pm 0.56 t$ & $3.11 \pm 0.38 \S$ & $44 \pm 3 \S$ \\
\hline
\end{tabular}

Abbreviations used in this table: (TF/P)In, tubular fluid:plasma inulin concentration ratio; RF, fraction remaining.

* Values are mean \pm SEM.

t Significantly different from control: $P<0.05$.

\$ Significantly different from control: $P<0.001$. 


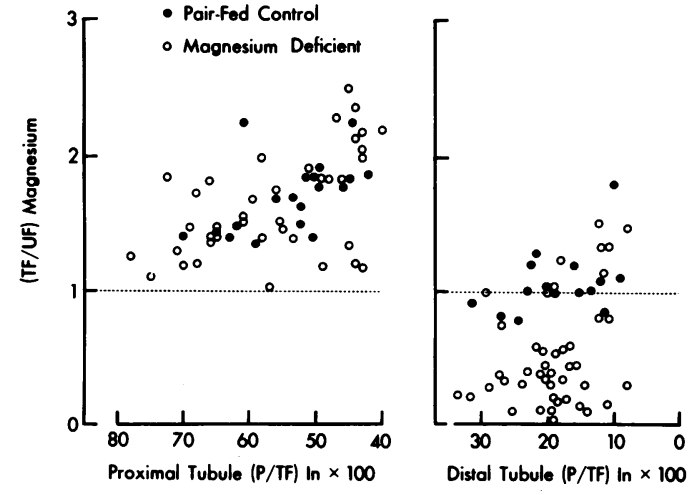

FIGURE 1 Comparison of proximal and distal micropuncture data during the control phase from six pair-fed and nine magnesium-deficient TPTX rats. Abscissa: percentage of filtrate remaining at the collection site as measured by $(\mathrm{P} / \mathrm{TF})$ In. Ordinate: $\mathrm{TF} / \mathrm{UF}_{\mathrm{Mg}}$.

phases. Plasma and urinary electrolyte values were similar to the above rats and remained constant throughout the period of micropuncture. The results of these time controls are given in Table IV. No significant changes were observed in any of the parameters measured throughout the duration of these control experiments.

Mg I and then Mg II loading increased the plasma magnesium levels in stepwise fashion to almost twice normal, and caused a graded elevation of fractional magnesium excretion in both normal and magnesiumdeficient rats to between 40 and $50 \%$ of the filtered load. Whole kidney GFR and single nephron GFR were not altered in both normal $(31 \pm 5$ to $29 \pm 5$ and $31 \pm 4 \mathrm{nl} / \mathrm{min}$, respectively; $n=5$ ) and magnesium- deficient $(25 \pm 3$ to $24 \pm 4$ and $27 \pm 4 \mathrm{nl} / \mathrm{min} ; n=8)$ rats with graded magnesium infusion. Small reductions in mean hematocrit and plasma albumin concentrations were noted in both groups, and urine flow increased, particularly in the normal rats. Proximal water reabsorption was inhibited to a modest extent with magnesium chloride infusion in normal rats, and no change was observed in the magnesium-deficient animals (Table II). Regression analyses of proximal tubule samples both before and after magnesium infusion by comparing the $(\mathrm{TF} / \mathrm{UF})_{\mathrm{Mg}}$ with the fraction of glomerular filtrate remaining are illustrated in Fig. 2 and regression analyses for the normal group $(n=19)$ was: (a) control: $y=2.69-0.02 x, r=0.60, P<0.05$; (b) $\mathrm{Mg}$ I: $y=2.93-0.02 x, r=0.57, P<0.05$; (c) $\mathrm{Mg}$ II: $y=2.35-0.01 x, r=0.73, P<0.01$; whereas in the magnesium-deficient group $(n=21)$ it was: (a) $y$ $=2.86-0.02 x, r=0.55, P<0.05 ;(b) y=2.91-0.02 x$, $r=0.78, P<0.001 ;$ (c) $y=2.71-0.02 x, r=0.54$, $P<0.05$, respectively. Thus there were no significant alterations in the percentage of filtered magnesium reabsorbed within the proximal tubule after magnesium loading in either normal or magnesiumdeficient rats, although absolute reabsorption (microequivalents per minute) was comparatively greater in the former group as a result of the larger filtered load (Table III). Within the early distal tubule, the mean $(\mathrm{TF} / \mathrm{UF})_{\mathrm{Mg}}$ was found to increase in control pair-fed rats from 0.99 progressively to 2.12 after graded magnesium loading, and in the magnesium-deficient group this ratio increased from 0.43 progressively to 2.17 . This resulted in an overall reduction of fractional reabsorption in both normal and deficient animals. This

TABLE III

Percentage and Absolute Magnesium Reabsorption between Superficial Tubule Puncture Sites in Pair-fed Control Rats and Magnesium-deficient TPTX Rats*

\begin{tabular}{|c|c|c|c|c|c|c|}
\hline & \multicolumn{3}{|c|}{ Pair-fed control } & \multicolumn{3}{|c|}{ Mg deficient } \\
\hline & Control & Mg I & Mg II & Control & Mg I & Mg II \\
\hline $\begin{array}{l}\text { Proximal tubule, \% } \\
\text { Abs, } \mu e q / \min \end{array}$ & $\begin{array}{c}14 \pm 2 \\
0.34 \pm 0.06\end{array}$ & $\begin{array}{c}10 \pm 4 \\
0.30 \pm 0.06\end{array}$ & $\begin{array}{c}14 \pm 3 \\
0.54 \pm 0.08 \ddagger\end{array}$ & $\begin{array}{c}16 \pm 6 \\
0.16 \pm 0.05\end{array}$ & $\begin{array}{c}7 \pm 4 \\
0.12 \pm 0.05\end{array}$ & $\begin{array}{c}11 \pm 4 \\
0.31 \pm 0.07 t\end{array}$ \\
\hline $\begin{array}{l}\text { Loop of henle, \% } \\
\text { Abs, req/min }\end{array}$ & $\begin{array}{c}63 \pm 4 \\
1.54 \pm 0.09\end{array}$ & $\begin{array}{c}52 \pm 4 \ddagger \\
1.47 \pm 0.10\end{array}$ & $\begin{array}{c}36 \pm 3 \S \\
1.38 \pm 0.09 \ddagger\end{array}$ & $\begin{array}{c}75 \pm 3 \\
0.74 \pm 0.04\end{array}$ & $\begin{array}{c}68 \pm 5 \\
1.05 \pm 0.08\end{array}$ & $\begin{array}{c}40 \pm 4 \oint \\
1.20 \pm 0.10 \$\end{array}$ \\
\hline $\begin{array}{l}\text { Distal tubule, \% } \\
\text { Abs, req/min }\end{array}$ & $\begin{array}{c}6 \pm 1 \\
0.14 \pm 0.02\end{array}$ & $\begin{array}{c}9 \pm 2 \\
0.28 \pm 0.05 t\end{array}$ & $\begin{array}{c}4 \pm 1 \\
0.16 \pm 0.04\end{array}$ & $\begin{array}{c}0.4 \pm 1 \\
0.01 \pm 0.01\end{array}$ & $\begin{array}{c}4 \pm 1 \\
0.07 \pm 0.02\end{array}$ & $\begin{array}{c}5 \pm 1 \S \\
0.15 \pm 0.02 \S\end{array}$ \\
\hline $\begin{array}{l}\text { Distal minus urine, \% } \\
\text { Abs, } \mu e q / \min \end{array}$ & $\begin{array}{c}2 \pm 1 \\
0.06 \pm 0.01\end{array}$ & $\begin{array}{c}1 \pm 1 \\
0.01 \pm 0.01\end{array}$ & $\begin{array}{c}-5 \pm 1 \\
-0.18 \pm 0.04\end{array}$ & $\begin{array}{c}7 \pm 1 \\
0.07 \pm 0.01\end{array}$ & $\begin{array}{c}8 \pm 2 \\
0.12 \pm 0.03\end{array}$ & $\begin{array}{c}4 \pm 1 \\
0.12 \pm 0.03\end{array}$ \\
\hline
\end{tabular}

Abbreviations used in this table: Abs, absolute reabsorption for both kidneys.

* Values are mean \pm SEM.

‡ Significantly different from control: $P<0.05$.

$\$$ Significantly different from control: $P<0.001$. 
TABLE IV

Mean Micropuncture Data from Time-control Experiments within Six TPTX Magnesium-deficient Rats*

\begin{tabular}{|c|c|c|c|c|c|c|c|c|c|}
\hline & \multicolumn{3}{|c|}{ Late proximal } & \multicolumn{3}{|c|}{ Early distal } & \multicolumn{3}{|c|}{ Late distal } \\
\hline & Control 1 & Control 2 & Control 3 & Control 1 & Control 2 & Control 3 & Control 1 & Control 2 & Control 3 \\
\hline$(\mathrm{TF} / \mathrm{P}) \mathbf{I n}$ & $2.13 \pm 0.06$ & $2.14 \pm 0.10$ & $2.03 \pm 0.09$ & $4.25 \pm 0.25$ & $4.14 \pm 0.37$ & $4.14 \pm 0.21$ & $7.95 \pm 0.85$ & $8.28 \pm 0.74$ & $7.88 \pm 0.37$ \\
\hline$(\mathrm{TF} / \mathrm{UF})_{\mathrm{Mg}}$ & $1.77 \pm 0.12$ & $1.58 \pm 0.15$ & $1.69 \pm 0.11$ & $0.37 \pm 0.08$ & $0.47 \pm 0.10$ & $0.39 \pm 0.05$ & $0.73 \pm 0.20$ & $0.96 \pm 0.20$ & $0.86 \pm 0.23$ \\
\hline $\mathrm{RF}_{\mathrm{Mg}}, \%$ & $83 \pm 5$ & $76 \pm 2$ & $84 \pm 4$ & $9 \pm 1$ & $9 \pm 1$ & $8 \pm 1$ & $9 \pm 1$ & $13 \pm 2$ & $9 \pm 1$ \\
\hline$(\mathrm{TF} / \mathrm{UF})_{\mathrm{Ca}}$ & $1.08 \pm 0.06$ & $1.13 \pm 0.05$ & $1.09 \pm 0.04$ & $0.27 \pm 0.06$ & $0.28 \pm 0.04$ & $0.25 \pm 0.04$ & $0.31 \pm 0.04$ & $0.35 \pm 0.08$ & $0.28 \pm 0.05$ \\
\hline $\mathbf{R F}_{\text {Ca }}, \%$ & $51 \pm 3$ & $54 \pm 4$ & $55 \pm 4$ & $7 \pm 4$ & $8 \pm 2$ & $6 \pm 2$ & $4 \pm 1$ & $4 \pm 1$ & $3 \pm 1$ \\
\hline$(\mathrm{TF} / \mathrm{P}) \mathrm{Na}$ & $1.02 \pm 0.03$ & $1.00 \pm 0.01$ & $1.00 \pm 0.03$ & $0.29 \pm 0.03$ & $0.32 \pm 0.05$ & $0.30 \pm 0.03$ & $0.35 \pm 0.06$ & $0.40 \pm 0.10$ & $0.35 \pm 0.06$ \\
\hline $\mathrm{RF}_{\mathrm{Na}}, \%$ & $48 \pm 2$ & $48 \pm 2$ & $50 \pm 3$ & $7 \pm 1$ & $9 \pm 2$ & $7 \pm 1$ & $4 \pm 1$ & $5 \pm 1$ & $4 \pm 1$ \\
\hline$(\mathrm{TF} / \mathrm{P}) \mathrm{Pi}$ & $0.08 \pm 0.01$ & $0.12 \pm 0.03$ & $0.11 \pm 0.02$ & $0.13 \pm 0.03$ & $0.14 \pm 0.03$ & $0.13 \pm 0.04$ & $0.24 \pm 0.06$ & $0.23 \pm 0.08$ & $0.19 \pm 0.06$ \\
\hline $\mathbf{R F}_{\mathrm{Pi}}, \%$ & $4 \pm 1$ & $6 \pm 2$ & $5 \pm 1$ & $3 \pm 1$ & $4 \pm 1$ & $3 \pm 1$ & $3 \pm 1$ & $3 \pm 1$ & $2 \pm 1$ \\
\hline
\end{tabular}

Abbreviations used in this table: $\mathrm{RF}$, fraction remaining.

*Values are mean \pm SEM.

is illustrated in Fig. 3 for both groups of rats. Absolute magnesium reabsorption between the late proximal and early distal puncture sites showed that whereas absolute reabsorption decreased in normal rats (from $1.54 \pm 0.09$ to $1.38 \pm 0.09 \mu \mathrm{eq} / \mathrm{min}, P<0.05$ ), reabsorption in the magnesium-depleted group progressively increased from $0.74 \pm 0.04$ to $1.05 \pm 0.08$ and finally to $1.20 \pm 0.10 \mu \mathrm{eq} / \mathrm{min}$ (Fig. 4). However, absolute magnesium reabsorption by the loop of Henle was $18 \%$ less in magnesium-deficient rats than normal rats at comparable delivered loads $(1.20 \pm 0.10$ compared with $1.47 \pm 0.10 \mu \mathrm{eq} / \mathrm{min}, P<0.05)$. Furthermore, comparison of the filtered magnesium load presented to the whole kidney and the overall renal reabsorptive rate, also given in Fig. 4, portrays a similar picture at comparable filtered loads as that observed for the loop of Henle. Overall renal magnesium reabsorption was $23 \%$

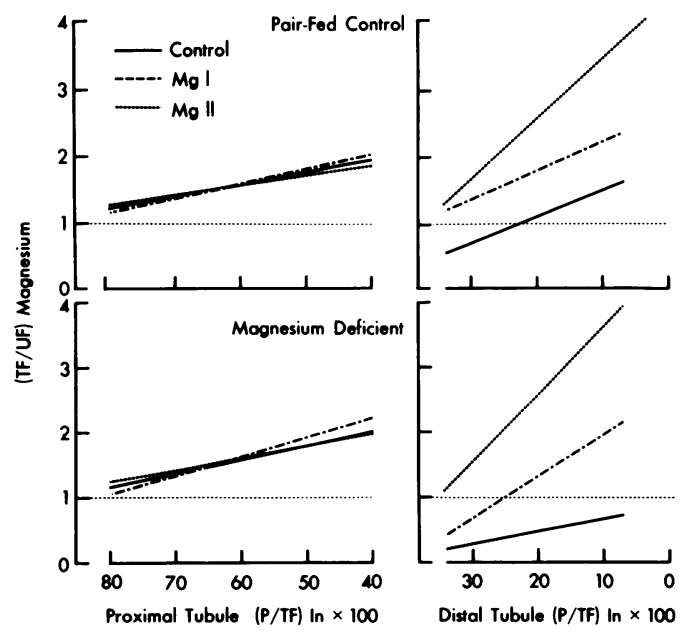

Figure 2 Effect of $\mathrm{Mg}$ I and Mg II infusion on the relationships between (TF/UF) $)_{\mathrm{Mg}}$ and the percentage of glomerular filtrate remaining in both proximal and distal tubules of normal (upper panel) and magnesium-deficient (lower panel) TPTX rats. less than normal in the magnesium-deficient group at similar filtered loads. The percentage of filtered magnesium reabsorbed within the distal tubule remained relatively constant in the control pair-fed group after magnesium infusion and demonstrates the limited transport capacity in this segment compared with the proximal tubule and loop of Henle. Elevation of the tubular fluid magnesium in magnesium-deficient animals was associated with a distal reabsorptive rate which was similar to that found in the normal rats with equivalent delivered loads. Distal $(\mathrm{TF} / \mathrm{UF})_{\mathrm{Mg}}$ as a function of water reabsorption (plasma:tubular fluid inulin concentration ratio $[(\mathrm{P} / \mathrm{TF}) \mathrm{In}])$ was examined with linear regression analysis and is illustrated in Fig. 2 . The distal regression analysis for the normal group $(n=17)$ were $(a)$ control: $y=1.92-0.04 x, r=0.50$, $P<0.05$; (b) Mg I: $y=2.67-0.04 x, r=0.49, P<0.05$; (c) Mg II: $y=4.38-0.09 x, r=0.73, P<0.001$; and for the magnesium-deficient group $(n=27)$ they were $(a)$ control: $y=0.86-0.02 x, r=0.38,0.1>P>0.05$; $(b)$ $\mathrm{Mg} \mathrm{I}: y=2.58-0.06 x, r=0.45, P=0.05 ;(c) \mathrm{Mg}$ II: $y=4.73-0.11 x, \quad r=0.59, P<0.001$ where the dependent variable is $(\mathrm{TF} / \mathrm{UF})_{\mathrm{Mg}}$ and the independent variable $(\mathrm{P} / \mathrm{TF})$ In along the distal tubule. Analysis in

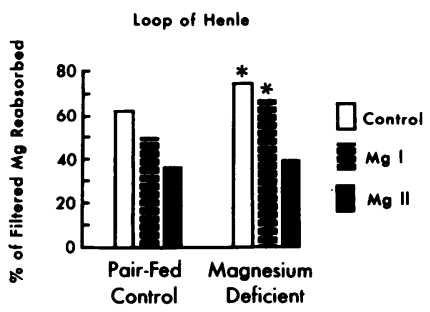

Figure 3 Comparison of the percentage of filtered magnesium reabsorbed by the loop of Henle in pair-fed and magnesium-deficient TPTX rats before and during graded magnesium infusion. $\left(^{*}\right)$ Signifies that the percentage of reabsorption was significantly greater $(P<0.05)$ than comparable normal rats. 

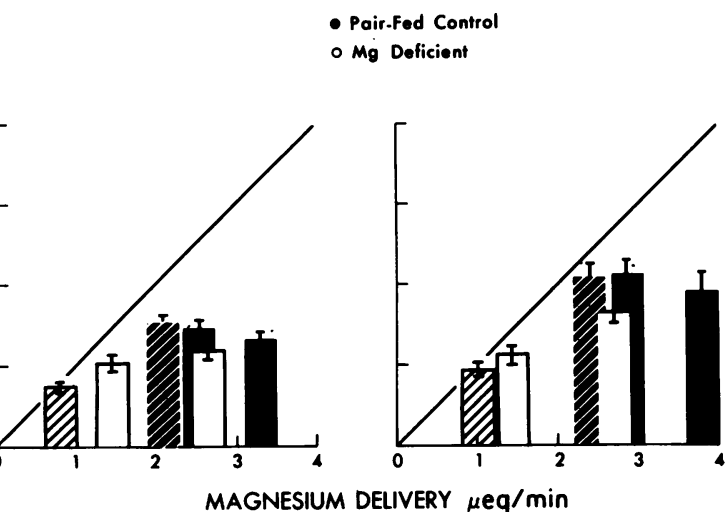

FIGURE 4 Relationship in normal and magnesium-deficient TPTX rats between the magnesium load delivered and the amount reabsorbed in the loop of Henle and the whole kidney. Control periods are given by the cross-hatched bars for each group of animals. Each point represents the mean \pm SEM.

the control phase of magnesiumdeficient experiments did not reach statistical significance; however, a combination of these results with values from the magnesium-deficient time-control rats did achieve significance $(y=0.97-0.02 x, n=44, r=0.43, P$ $<0.05$ ). Examination of the difference between the mean late distal puncture site and the final urine demonstrates little change in magnesium compared with the proximal and loop tubular segments.
Calcium. Plasma calcium concentrations were somewhat higher in the magnesium-deficient group when compared with the normal group after TPTX; however, the difference was not significant on an unpaired basis (Table I). Although the filtered load of calcium was similar during the control period in both groups, the fractional excretion of calcium was significantly greater in normal animals as compared with magnesium-deficient rats $(1.5 \pm 0.4$ compared with 0.7 $\pm 0.1 \%$, respectively, $P<0.05$ ). Table $\mathrm{V}$ gives the micropuncture data for normal and magnesiumdeficient TPTX rats during control and magnesium loading experiments. No differences were observed in calcium handling by the nephron between nopmal and magnesium-deficient rats. Graded magnesium infusion decreased plasma calcium concentration and progressively increased the fractional calcium excretion by similar amounts in both groups. The progressive and similar increases in calcium excretion in both normal and magnesium-deficient rats was a result of the additive reductions in calcium reabsorption in the proximal and the loop segments after graded magnesium chloride infusion. Proximal tubular fluid:ultrafilterable calcium ratios $\left[(\mathrm{TF} / \mathrm{UF})_{\mathrm{Ca}}\right]$ in the deficient rats showed a significant elevation after $\mathrm{Mg} \mathrm{I}$; however, this did not differ from subsequent phases in normal animals. The major portion of the excreted calcium in both magnesium-deficient and control pair-fed rats resulted from inhibition of calcium reabsorption within the loop of Henle. Absolute distal reabsorption was unaltered by magnesium loading. Fractional urinary sodium in-

TABLE V

Mean Calcium Micropuncture Data from Pair-fed Control and Magnesium-deficient TPTX Rats during Control and after Graded Magnesium Infusion*

\begin{tabular}{|c|c|c|c|c|c|c|c|c|c|}
\hline & & & & \multicolumn{6}{|c|}{ Distal tubule } \\
\hline & \multicolumn{3}{|c|}{ Late proximal tubule } & \multicolumn{3}{|c|}{ Early } & \multicolumn{3}{|c|}{ Late } \\
\hline & (TF/P)In & $(\mathrm{TF} / \mathrm{UF})_{\mathrm{Ca}}$ & $\mathbf{R F}$ & $(\mathrm{TF} / \mathrm{P}) \mathbf{I n}$ & $(\mathrm{TF} / \mathrm{UF})_{\mathrm{Ca}}$ & $\mathbf{R F}$ & (TF/P)In & $(\mathrm{TF} / \mathrm{UF})_{\mathrm{Ca}}$ & $\mathrm{RF}$ \\
\hline & & & $\%$ & & & $\%$ & & & $\%$ \\
\hline \multicolumn{10}{|l|}{$\begin{array}{l}\text { Pair-fed } \\
\text { control } \\
(n=6)\end{array}$} \\
\hline Control & $2.08 \pm 0.05$ & $1.17 \pm 0.04$ & $57 \pm 2$ & $4.55 \pm 0.41$ & $0.30 \pm 0.04$ & $6 \pm 1$ & $8.57 \pm 0.68$ & $0.26 \pm 0.08$ & $3 \pm 1$ \\
\hline Mg I & $1.92 \pm 0.04$ & $1.24 \pm 0.05$ & $65 \pm 2 \ddagger$ & $4.32 \pm 0.24$ & $0.35 \pm 0.04$ & $8 \pm 1$ & $7.63 \pm 0.73$ & $0.38 \pm 0.07$ & $5 \pm 1$ \\
\hline Mg II & $1.94 \pm 0.08$ & $1.22 \pm 0.03$ & $64 \pm 2 \ddagger$ & $4.30 \pm 0.20$ & $0.43 \pm 0.06$ & $10 \pm 2$ & $6.78 \pm 0.63$ & $0.41 \pm 0.06$ & $7 \pm 1$ \\
\hline \multicolumn{10}{|c|}{$\begin{array}{c}\text { Magnesium } \\
\text { deficient } \\
(n=9)\end{array}$} \\
\hline Control & $2.18 \pm 0.06$ & $1.07 \pm 0.05$ & $50 \pm 3$ & $4.60 \pm 0.19$ & $0.25 \pm 0.03$ & $5 \pm 1$ & $7.68 \pm 0.60$ & $0.27 \pm 0.07$ & $4 \pm 1$ \\
\hline Mg I & $1.96 \pm 0.08$ & $1.23 \pm 0.03 \ddagger$ & $64 \pm 2 \ddagger$ & $4.61 \pm 0.25$ & $0.33 \pm 0.06 \ddagger$ & $7 \pm 1$ & $7.01 \pm 0.51 \ddagger$ & $0.41 \pm 0.09 \ddagger$ & $6 \pm 2$ \\
\hline Mg II & $1.93 \pm 0.06$ & $1.25 \pm 0.06$ & $65 \pm 3 \ddagger$ & $4.38 \pm 0.28$ & $0.45 \pm 0.04 \ddagger$ & $10 \pm 1 \ddagger$ & $7.19 \pm 0.56 \ddagger$ & $0.50 \pm 0.07 \ddagger$ & $8 \pm 1 \neq$ \\
\hline
\end{tabular}

Abbreviations used in this table: RF, fraction remaining.

* Values are mean $\pm \mathrm{SEM}$.

† Significantly different from control: $P<0.05$. 
creased in both groups after graded magnesium chloride loading (Table I). This resulted from a $5-10 \%$ fall in proximal sodium reabsorption which escaped into the final urine. The fraction of sodium remaining at the late proximal sampling site was $50 \pm 3 \%$ in the control first phase of boths series and increased in a similar manner to $60 \pm 2$ and $62 \pm 3 \%$, respectively, with graded increases in plasma magnesium. Little change was observed in the loop of Henle and distal segments. This resulted in modest increases in urinary sodium excretion compared with the more striking increases in fractional calcium excretion.

Inorganic phosphate. Magnesium-deficient TPTX rats remained modestly hypophosphatemic when compared with normal TPTX animals during the control phase; however, the fractional excretion of phosphate was small and nondistinguishable (0.1\%) between both groups. No differences were noted in tubular fluid phosphorus concentrations between the two groups, nor was there any marked change in renal handling of phosphorus after acute elevation of plasma magnesium.

\section{DISCUSSION}

Dietary magnesium restriction leads to hypercalcemia in rats in contrast to man and other animals which develop hypocalcemia $(5,8-10,18-20)$. The rats in our studies were not significantly hypercalcemic, but the plasma calcium was on the high side of normal, which may have indicated a modest positive calcium balance. In addition to reduction in extracellular and intracellular magnesium concentration, magnesiumdeficient rats demonstrate a low intracellular potassium $(5,18,19)$ and a mild hypophosphatemia. Our results must be interpreted in light of these electrolyte balances.

Magnesium. In our studies with normal TPTX rats, $\sim 14 \%$ of filtered magnesium was reabsorbed by the superficial proximal tubule, compared with $52 \%$ of the filtered water. This relatively low reabsorptive rate for magnesium in comparison with that of sodium and calcium is in keeping with recent experimental results in parathyroid-intact $(2,21-23)$ and TPTX rats (24). Furthermore, recent experiments in the dog (3) suggest that this animal species is similar to the rat. Subsequent to dietary magnesium deprivation, mean late proximal $(\mathrm{TF} / \mathrm{UF})_{\mathrm{Mg}}$ and the percentage of filtered magnesium reabsorbed by the proximal tubule remained unchanged despite a $50 \%$ reduction in ultrafilterable magnesium. Acute magnesium infusion did not alter the (TF/UF $)_{\mathrm{Mg}}$ in either normal or magnesiumdeficient animals. This suggests that proximal magnesium reabsorption is unaffected by body magnesium status, although factors which depress proximal fluid reabsorption will accordingly depress the fractional reabsorption of filtered magnesium.
The loop of Henle was found to be the major site of magnesium reabsorption in both pair-fed control and depleted rats. Net reabsorption amounted to some 63 and $75 \%$ of the respective filtered loads. The nephron segment termed the loop contains all segments between the late proximal and early distal puncture site; however, studies by de Rouffignac et al. (25) and Brunette et al. (23) have demonstrated the ascending limb is the major segment involved in magnesium reclamation. Although fractional reabsorption was greater in the loop segments of magnesium-deficient animals, which accounted for the difference in fractional urinary excretion between the two groups, absolute magnesium reabsorption within the loop was greater in the pair-fed control rats because of the greater magnesium delivery. We further investigated this anomaly by exposing the kidney to graded magnesium loads. After magnesium infusion fractional reabsorption decreased in normal rats within the loop of Henle. Elevation of the filtered magnesium load in magnesium-deficient rats also depressed fractional loop reabsorption as well as fractional whole kidney magnesium reabsorption. However, in contrast to normal animals, absolute magnesium reabsorption increased in magnesium-deficient rats receiving a magnesium load, but at comparable filtered and delivered loads, both the loop of Henle and whole kidney magnesium reabsorption were less than the pair-fed control group. Thus, presenting the loop of Henle with similar magnesium loads produces a fall in absolute reabsorption in pair-fed rats and an increase in depleted animals; but, importantly, these do not increase to normal levels in the latter group. These findings in the magnesium-deficient rat may reflect an acquired reabsorptive defect in the loop or, alternatively, the reabsorptive capacity may be dependent upon intracellular magnesium concentration. Magnesium-deficient animals presumably have a relatively lower extracellular magnesium pool compared with normal rats. Acute magnesium infusion may not immediately replete this supply. The mechanisms for magnesium reabsorption within the loop of Henle are not understood although the thick ascending limb is considered to be the major site $(23,25)$. Microperfusion experiments within our laboratory $(26,27)$ suggest that magnesium transport is mainly unidirectional as significant luminal backflux was neither observed in the loop of Henle nor in the proximal or distal tubules after in vivo perfusion with magnesiumfree solutions. This would suggest that the relatively lower capacity to transport magnesium is not a result of enhanced backflux. Furthermore, elevation of plasma magnesium but not luminal magnesium resulted in a specific inhibition of magnesium transport in the loop of Henle. This presumably was located at the contraluminal membrane of the thick ascending limb. Another explanation may include the dependency on chloride transport within the thick ascending limb. 
If active chloride transport, which was not altered in magnesium deficiency, was the principal driving force for magnesium, the rate-limiting step for magnesium at the contraluminal membrane (26) may be more dependent upon relative intracellular and extracellular magnesium concentration than normal animals $(26,27)$. Although the role of parathyroid hormone is not well defined, most studies suggest that in the absence of hypercalcemia parathyroid hormone enhances renal magnesium reabsorption $(28,29)$. Also, because magnesium conservation during magnesium-deficient diet is impaired after TPTX (30) it is possible that parathyroid hormone acts within the loop of Henle. The role of parathyroid hormone in renal magnesium handling requires further attention, especially with regard to magnesium deficiency. Additionally, these magnesium-deficient rats may have been modestly phosphate depleted and hypercalcemic. These factors have been shown to alter magnesium transport beyond the proximal tubule $(31,32)$. Further studies are required to elucidate the mechanism of the depressed reabsorptive capacity in magnesium deficiency.

Magnesium reabsorption within the distal tubule was found to be minimal during magnesium deficiency, but after magnesium loading and elevation of the tubular fluid magnesium, a small amount of magnesium reabsorption occurred similar to that noted in pair-fed rats with comparable deliveries. This suggests that an increase in the distal $(\mathrm{TF} / \mathrm{UF})_{\mathrm{Mg}}$ may facilitate magnesium transport across a relatively impermeable membrane. The analysis of magnesium handling by the collecting system simply by subtracting the fraction excreted in the urine from the rejected fraction at the late distal tubular puncture site is unreliable because of problems of nephron heterogeneity, and because most magnesium is reabsorbed within the loop of Henle it is possible that the juxtamedullary nephrons reabsorb more magnesium than superficial nephrons, thus, accounting for the differences observed between the superficial distal tubule and the final urine. Yet, with water abstraction and a consequent increase in magnesium concentration within the hypertonic medulla, a small reabsorptive capacity may occur and could be important during magnesium depletion.

Calcium. Calcium handling along the renal nephron was similar in magnesium-deficient TPTX rats and pair-fed normomagnesemic TPTX animals, although the urinary excretion was significantly less in the deficient groups. Graded elevation of plasma magnesium resulted in similar progressive increases in fractional urinary calcium excretion in both series of animals. Micropuncture analysis revealed an inhibition of proximal calcium reabsorption of some $5-10 \%$ which was similar to that observed for proximal sodium reclamation. Calcium was inhibited more specifically in the loop of Henle as reflected by the significantly different calcium concentration in the early distal collections.
Moreover, this specific effect was quantitatively similar in both pair-fed control and magnesium-deficient rats. Thus, overall urinary calcium excretion in contrast to sodium was a reflection of interaction within the loop of Henle and supports our previous findings $(26,27)$.

Sodium and phosphate handling was similar in both normal TPTX rats as in magnesium-deficient TPTX rats. Magnesium infusion resulted in depressed proximal sodium reabsorption which caused a modest natriuresis.

In summary, dietary magnesium deprivation results in a fall in fractional urinary magnesium excretion proportional to a fall in filtered load (plasma concentration). This was mainly a reflection of the loop of Henle because fractional reabsorption remained similar to control rats in the superficial proximal and distal tubule. Absolute reabsorption was markedly less in magnesium-deficient animals. Graded magnesium infusion resulted in overall absolute increases in magnesium reabsorption in both control and magnesiumdeficient rats; however, the deficient animals possessed a lower reabsorptive capacity. This requires further investigations to delineate the cellular etiology. This investigation is the first micropuncture study of the renal handling of magnesium and calcium in magnesium deficiency and, as such, delineates the reabsorptive capacity of the loop of Henle in this deficiency syndrome.

\section{ACKNOWLEDGMENTS}

The authors gratefully acknowledge the expert technical assistance of Mr. Ray Dierolf, Mr. David Ridout, Mrs. Sylvia Deare, and Mrs. Monique Julita, and the superb typing expertise of Mr. Gordon Phillips and Mrs. Pat Pinder.

This study was supported by Medical Research Council (Canada) grants to Dr. Dirks (MT-1915 and MA-5431) and Dr. Quamme (MA-5793).

\section{REFERENCES}

1. Morel, F., N. Roinel, and C. LeGrimellec. 1969. Electron probe analysis of tubular fluid composition. Nephron. 6: 350-364.

2. Brunette, M. G., N. Vigneault, and S. Carriere. 1974. Micropuncture study of magnesium transport along the nephron in the young rat. Am. J. Physiol. 227: 891-896.

3. Quamme, G. A., N. L. M. Wong, J. H. Dirks, N. Roinel, C. de Rouffignac, and F. Morel. 1978. Magnesium handling in the dog kidney: a micropuncture study. Pflugers Arch. Eur. J. Physiol. 377: 95-99.

4. Barnes, B. A., O. Cope, and T. Harrison. 1958. Magnesium conservation in the human being on a low magnesium diet. J. Clin. Invest. 37: 430-440.

5. Whang, R., and L. G. Welt. 1963. Observations in experimental magnesium depletion. J. Clin. Invest. 42: 305-313.

6. Chutkow, J. G. 1965. Studies on the metabolism of magnesium in the magnesium deficient rat. J. Lab. Clin. Med. 75: 912-926.

7. Shils, M. E. 1969. Experimental human magnesium depletion. Medicine (Baltimore). 48: 61-85.

8. Gitelman, H. J., S. Kukolj, and L. G. Welt. 1968. The 
influence of the parathyroid glands on the hypercalcemia of experimental magnesium depletion in the rat. J. Clin. Invest. 48: 118-126.

9. Hahn, T. J., L. R. Chase, and L. V. Avioli. 1972. Effect of magnesium depletion on responsiveness to parathyroid hormone in parathyroidectomized rats. J. Clin. Invest. 51: 886-891.

10. Martindale, L., and F. W. Heaton. 1964. Magnesium deficiency in the adult rat. Biochem. J. 92: 119-1236.

11. Heaton, F. W. 1965. The parathyroid glands and magnesium metabolism in the rat. Clin. Sci. (Oxf.). 28: 543553.

12. Averill, C. M., and F. W. Heaton. 1966. The renal handling of magnesium. Clin. Sci. (Oxf.). 31: 353-360.

13. Fuhr, J., J. Kaczmarczyk, and C. D. Kruttgen. 1955. Eine einfache colorimetrische Methode zur Inulinbestimmung fur Nierenclearance-untersuchungen bei Stoffwechselgesunden und Diabetikern. Klin. Wochenschr. 33: 729730.

14. Vurek, G. G., and S. E. Pegram. 1966. Fluorometric method for the determination of nanogram quantities of inulin. Anal. Biochem. 16: 409-419.

15. Chen, P. S., Jr., T. Y. Toribara, and H. Warner. 1956. Microdetermination of phosphorus. Anal. Chem. 28: 1756-1758.

16. Morel, F., and N. Roinel. 1969. Application de la microsonde electronique a l'analyse elementaire quantitative d'echantillons liquides d'un volume inferieur a $10^{-9} l$. J. Chim. Phys. 66: 1084-1091.

17. Greene, R. W., and L. A. Sapirstien. 1952. Total body sodium, potassium and nitrogen in rats made hypertensive by subtotal nephrectomy. Am. J. Physiol. 169: 343-349.

18. Reddy, C. R., J. W. Coburn, D. L. Hartenbower, R. M. Friedler, A. S. Brickman, S. G. Massry, and J. Jowsey. 1973. Studies on mechanisms of hypocalcemia of magnesium depletion. J. Clin. Invest. 52: 3000-3010.

19. Smith, B. S. W., and D. I. Nisbet. 1968. Biochemical and pathological studies on magnesium deficiency in the rat. I. Young animals. J. Comp. Pathol. 78: 149-162.

20. MacManus, J., and F. W. Heaton. 1969. The effect of magnesium deficiency on calcium homeostasis in the rat. Clin. Sci. (Oxf.). 36: 297-306.
21. LeGrimellec, C., N. Roinel, and F. Morel. 1973. Simultaneous $\mathrm{Mg}, \mathrm{Ca}, \mathrm{P}, \mathrm{K}, \mathrm{Na}$ and $\mathrm{Cl}$ analysis in rat tubular fluid. I. During perfusion of either inulin or ferrocyanide. Pflugers Arch. Eur. J. Physiol. 340: 181-196.

22. LeGrimellec, C., N. Roinel, and F. Morel. 1973. Simultaneous $\mathrm{Mg}, \mathrm{Ca}, \mathrm{P}, \mathrm{K}, \mathrm{Na}$ and $\mathrm{Cl}$ analysis in rat tubular fluid. II. During acute $\mathrm{Mg}$ plasma loading. Pflugers Arch. Eur. J. Physiol. 340: 197-210.

23. Brunette, M. G., N. Vigneault, and S. Carriere. 1975. Micropuncture study of renal magnesium transport in magnesium loaded rats. Am. J. Physiol. 229: 1695-1701.

24. Kuntzinger, H., C. Amiel, N. Roinel, and F. Morel. 1974. Effects of parathyroidectomy and cyclic AMP on renal transport of phosphate, calcium, and magnesium. Am.J. Physiol. 227: 905-911.

25. De Rouffignac, C., F. Morel, N. Moss, and N. Roinel. 1973. Micropuncture study of water and electrolyte movements along the loop of Henle in Psammomys with special reference to magnesium, calcium and phosphorus. Pflugers Arch. Eur. J. Physiol. 344: 309-326.

26. Quamme, G. A., and J. H. Dirks. 1977. Microperfusion studies of magnesium transport in the proximal tubule and loop of Henle of the rat. Clin. Res. 25: 707A. (Abstr.)

27. Quamme, G. A., and J. H. Dirks. 1979. Intraluminal and contraluminal magnesium on magnesium and calcium transfer in the rat nephron. Am. J. Physiol. In press.

28. MacIntyre, I., S. Boss, and V. A. Troughton. 1963. Parathyroid hormone and magnesium homeostasis. Nature (Lond.). 198: 1058-1060.

29. Bethune, J. E., R. A. Turpin, and H. Inoue. 1968. Effect of parathyroid hormone extract on divalent ion excretion in man. J. Clin. Endocrinol. Metab. 28: 673-678.

30. Walser, M. 1969. Renal excretion of alkaline earths. In Mineral Metabolism. C. L. Comar and F. Bronner, editors. Academic Press, Inc., New York. III: 236-320.

31. Kreusser, W. J., K. Kurokawa, E. Aznar, E. Sachtjen, and S. G. Massry. 1978. Effect of phosphate depletion on magnesium homeostasis in rats. J. Clin. Invest. 61: 573581 .

32. Blassnig, R., and G. A. Quamme. 1978. Effect of hypercalcemia on calcium and magnesium transport along the loop of Henle and distal tubule. Clin. Res. 26: 867A. (Abstr.) 